\title{
One-Dimensional Peptide Nanostructure Templated Growth of Iron Phosphate Nanostructures for Lithium-Ion Battery Cathodes
}

\author{
Hepi Hari Susapto, ${ }^{\S, \dagger}$ O. Ulas Kudu, ${ }^{\dagger}$ Ruslan Garifullin, ${ }^{\dagger, \dagger}$ Eda Y1lmaz, ${ }^{* \dagger}$ and Mustafa O. Guler ${ }^{*}, \dagger$ \\ ${ }^{\dagger}$ Institute of Materials Science and Nanotechnology, National Nanotechnology Research Center, Bilkent University, Ankara 06800, \\ Turkey \\ ${ }^{\ddagger}$ Kazan Federal University, Institute of Fundamental Medicine and Biology, 18 Kremlyovskaya St., 420008 Kazan, Russian Federation
}

Supporting Information

ABSTRACT: Template-directed synthesis of nanomaterials can provide benefits such as small crystalline size, high surface area, large surface-to-volume ratio, and structural stability. These properties are important for shorter distance in ion/electron movement and better electrode surface/electrolyte contact for energy storage applications. Here nanostructured $\mathrm{FePO}_{4}$ cathode materials were synthesized by using peptide nanostructures as a template inspired by biomineralization process. The amorphous, high surface area $\mathrm{FePO}_{4}$ nanostructures were utilized as a cathode for lithium-ion batteries. Discharge capacity of $155 \mathrm{mAh} / \mathrm{g}$ was achieved at $\mathrm{C} / 20$ current rate. The superior properties of biotemplated and nanostructured amorphous $\mathrm{FePO}_{4}$ are shown compared to template-free crystalline $\mathrm{FePO}_{4}$.

KEYWORDS: peptide amphiphile, self-assembly, hydrogel, nanofiber, nanobelt, template-directed materials

\section{INTRODUCTION}

High demand for portable electronic devices and electric and hybrid vehicles has increased the need for secondary batteries in the past decade. Lithium-ion batteries (LIBs) are currently the most prevalent secondary battery systems due to their high energy density, high voltage, light weight, and long cycle life. ${ }^{1-4}$ Selection and synthesis of the electrode materials are very crucial to utilize these properties appropriately. Lithium transition metal oxides $\left(\mathrm{LiMO}_{x}, \mathrm{M}\right.$ is a transition metal) are conventionally used as cathode materials for LIBs; however, there are some safety concerns associated with these materials, because they release oxygen from the lattice at high temperatures. ${ }^{5}$ To increase the safety of cathode materials, materials with polyanion groups have been investigated. ${ }^{6-8}$ On the one hand, olivine lithium iron phosphate $\left(\mathrm{LiFePO}_{4}\right)$ has been studied as cathode material due to its high stability and thermal safety, good theoretical capacity $(\sim 170 \mathrm{mAh} / \mathrm{g})$, and low material cost. ${ }^{9-11}$ On the other hand, olivine structure has slow $\mathrm{Li}^{+}$ion and electron transfer, which leads to a poor rate capability. ${ }^{12,13}$ Alternatively, amorphous iron phosphate $\left(\mathrm{FePO}_{4}\right)$ has received increasing attention because it is stable, safe, cheaper, and has a slightly higher theoretical capacity $(\sim 178 \mathrm{mAh} / \mathrm{g}) .{ }^{14}$ Moreover, it has a continuous charge-discharge voltage profile, which makes it easier to monitor the state of charge of the battery. ${ }^{4}$ However, as amorphous $\mathrm{FePO}_{4}$ suffers from low ionic and electronic conductivity, its practical capacity is dramatically lower than the theoretical value. ${ }^{15,16}$ Several attempts have been shown to be effective such as nanostructures, ${ }^{17-19}$ carbon nanopainting, ${ }^{20}$ and conductive additives. ${ }^{21,22}$ By using template-directed synthesis methods, nanostructures with desired shape, size, and function can be achieved. ${ }^{23-25}$ These materials usually have small crystalline size, high surface area, large surface-to-volume ratio, and favorable structural stability, which result in shorter distance for ion/electron movement and better electrode surface/ electrolyte contact. ${ }^{26}$ All these properties eventually lead to higher overall capacity, rate capability, and battery life.

Biotemplating is an efficient way to synthesize environmentally friendly, ordered, and reproducible materials. ${ }^{27}$ Biomineralization process was previously utilized for reaching these targets. ${ }^{27,28}$ Previously, crystalline $\mathrm{FePO}_{4}$ hollow nanospheres with diameters of $7 \mu \mathrm{m}$ were produced by using rape pollen grains as a template, but their electrochemical performance was not studied. ${ }^{27}$ Amorphous $\mathrm{FePO}_{4}$ nanowires with diameters of 10 to $20 \mathrm{~nm}$ were synthesized by using genetically engineered M13 virus, showing an initial specific capacity of 100 $\mathrm{mAh} / \mathrm{g}$ at a current rate of $\mathrm{C} / 10$. A heterostructured cathode material mixed with $\mathrm{AgCl}$ was synthesized by using biotemplating approach, and their discharge capacity was increased to 150 $\mathrm{mAh} / \mathrm{g}$ after cycling at the same current rate. ${ }^{28}$

In this work, we show synthesis of nanobelt- and nanotubeshaped iron phosphate $\left(\mathrm{FePO}_{4}\right)$ nanostructures by using peptide nanostructures as biotemplates. By exploiting the fascinating features of the amphiphilic peptide molecules such as ease of modification over the chemical functionality and architecture diversity, ${ }^{29}$ the nanonetworks were uniformly coated with a thin $\mathrm{FePO}_{4}(\sim 8 \mathrm{~nm})$ layer allowing the $\mathrm{Li}^{+}$ions to intercalate through

Received: February 29, 2016

Accepted: June 17, 2016

Published: June 17, 2016 

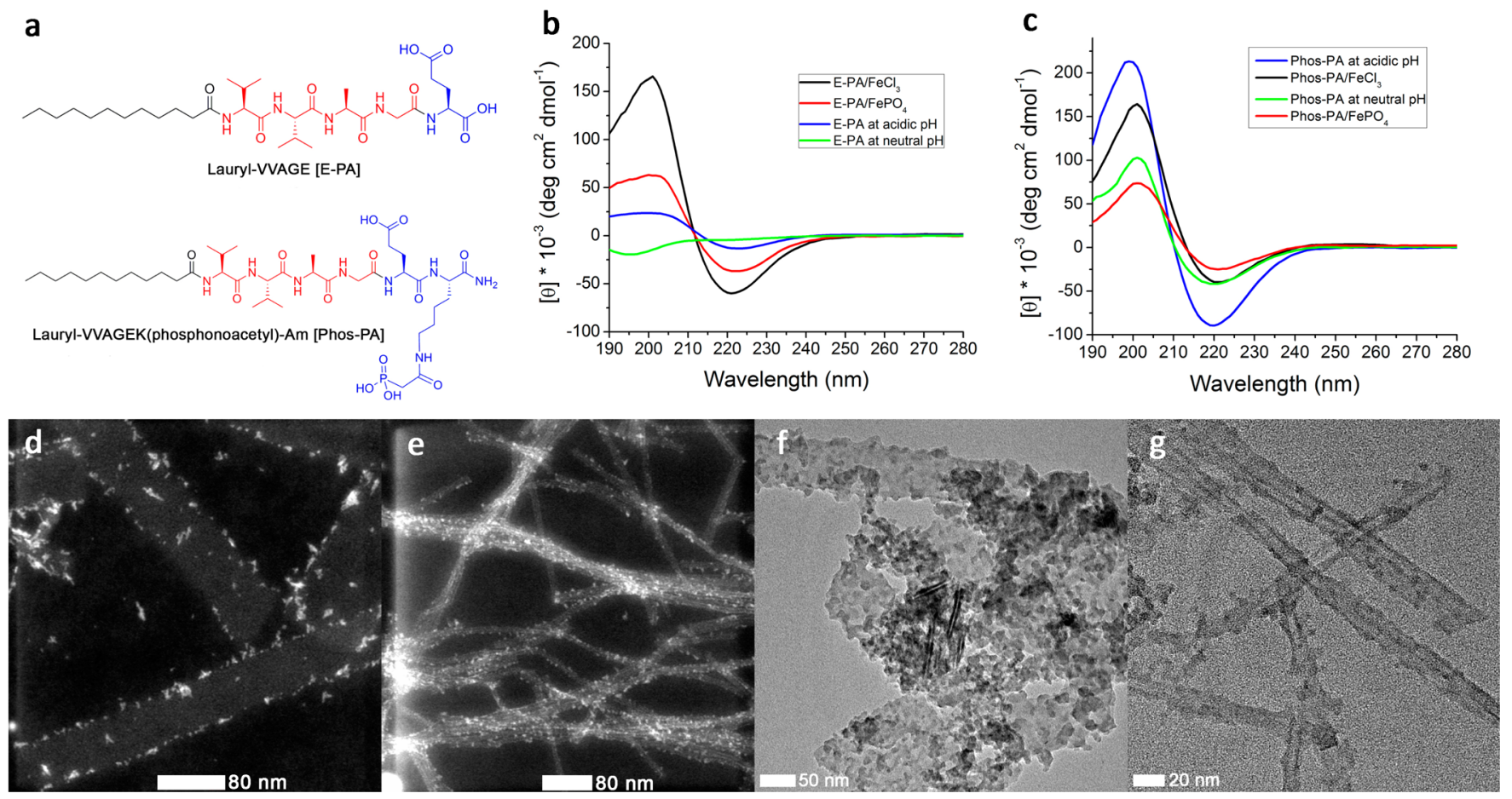

Figure 1. (a) Chemical structures of peptide amphiphile molecules. CD spectra of the secondary structure of peptide amphiphile interactions (b) E-PA and (c) Phos-PA. STEM and TEM images of self-assembled peptide amphiphiles with inorganic materials (d) STEM image of E-PA/FeCl 3 , (e) STEM image of Phos-PA/ $\mathrm{FeCl}_{3}$, (f) TEM image of uncalcined ETF, and (g) TEM image of uncalcined PTF.
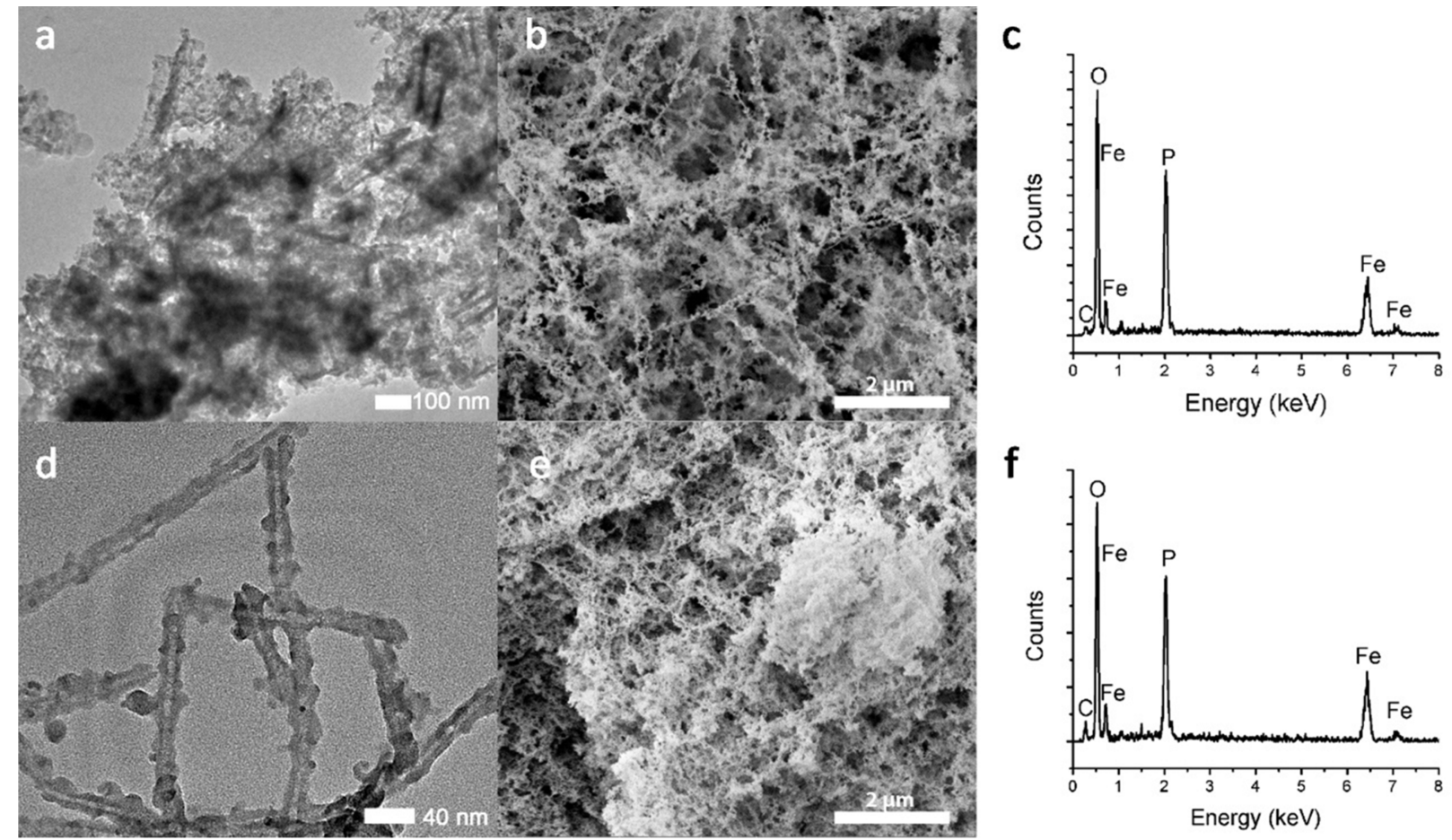

Figure 2. Morphology and composition of the calcined peptide nanostructures coated with inorganic materials. (a) TEM image of E-PA/FePO $(\mathrm{ETF})$, (b) SEM image of ETF, (c) EDX spectrum of ETF, (d) TEM image of Phos-PA/FePO ${ }_{4}$ (PTF), (e) SEM image of PTF, and (f) EDX spectrum of PTF.

shorter distances, to increase the electrochemical reaction kinetics and to reduce the concentration polarization effects. The $\mathrm{FePO}_{4}$ coated peptide nanonetworks were later calcined to remove the organic peptide template. Furthermore, multiwalled carbon nanotubes (MWCNTs) were mixed with the calcined
$\mathrm{FePO}_{4}$ nanostructures to improve the electronic conductivity of the cathode films.

\section{RESULTS AND DISCUSSION}

Two different peptide amphiphile molecules containing a hydrophobic alkyl tail, a short peptide sequence forming $\beta$ - 


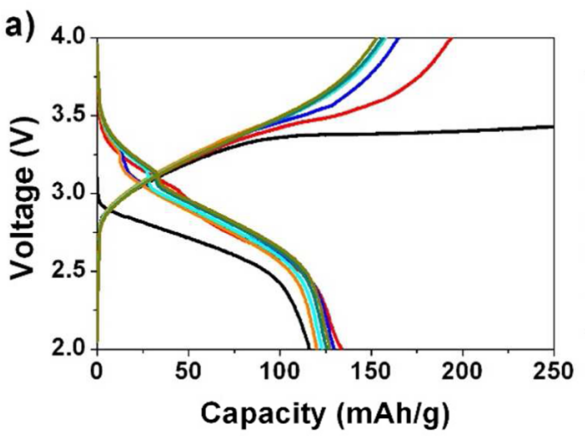

c)

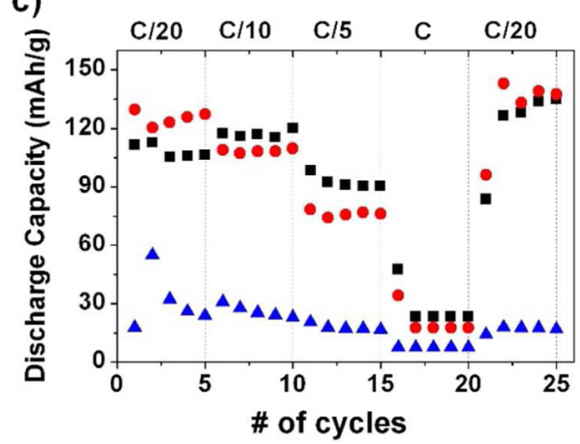

b)
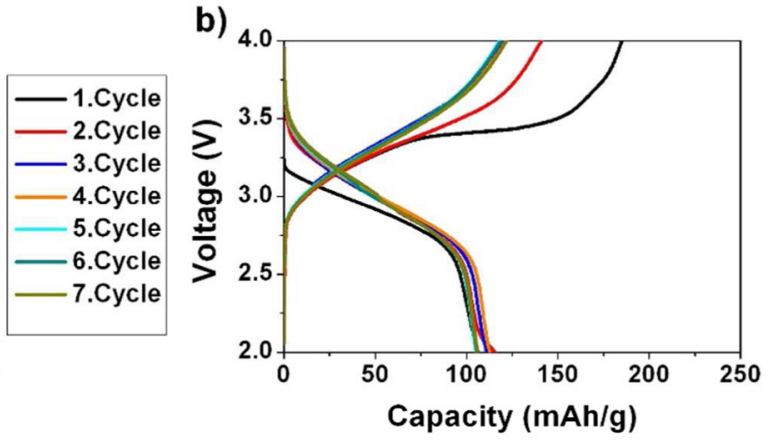

d)

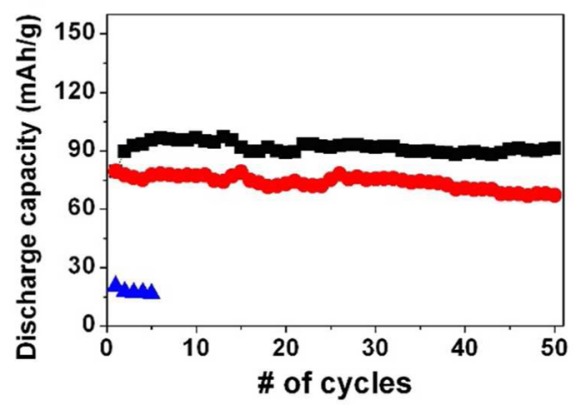

Figure 3. (a) Discharge-charge voltage profiles of the initial seven cycles of the ETF at C/20. (b) Discharge-charge voltage profiles of the initial seven cycles of the PTF at C/20. (c) The rate capability of the cathode materials, and (d) the cyclic stability of the discharge capacity of the cathode materials. ETF and PTF were tested at $\mathrm{C} / 2$ current rate; bulk $\mathrm{FePO}_{4}$ was tested at $\mathrm{C} / 5$ current rate.

sheet structure, and a charged headgroup were designed and synthesized. These peptide amphiphile molecules, LaurylVVAGEK(phosphonoacetyl)-Am [Phos-PA] and LaurylVVAGE [E-PA], can form nanostructures, and they were used as a template for $\mathrm{FePO}_{4}$ formation (Figure 1a). The purity of the peptide molecules was determined by using liquid chromatography-mass spectrometry analysis (Figure S1-S4, Supporting Information). The self-assembly of the peptides was triggered by $\mathrm{Fe}^{3+}$ addition, which results in the formation of $\beta$-sheet secondary structure that is essential for the formation of organic-inorganic core-shell materials. In addition, the functional groups at the periphery of the peptide nanostructures coordinate to $\mathrm{Fe}^{3+}$ ions providing the nucleation sites for the growth of the inorganic material on the surface of the nanostructures. Template-free (bulk) $\mathrm{FePO}_{4}$ was also synthesized by mixing the precursor materials in absence of the peptides. Electrochemical performance of the bulk material was analyzed and compared to those of the templated materials.

A gel was formed when peptide molecules self-assembled into nanostructures (Figure S5). The 1 wt $\% \mathrm{E}-\mathrm{PA} / \mathrm{FeCl}_{3}$ and Phos$\mathrm{PA} / \mathrm{FeCl}_{3}$ gels were mixed with $\mathrm{NaH}_{2} \mathrm{PO}_{4}$ to induce the formation of E-PA/ $\mathrm{FePO}_{4}$ (ETF) and Phos-PA/FePO $(\mathrm{PTF})$. The secondary structures of the self-assembled peptides were studied by using circular dichroism (CD) spectroscopy. Formation of $\beta$-sheet structure for all of the self-assembled systems was observed (Figure $1 \mathrm{~b}, \mathrm{c}$ ). ${ }^{30,31}$ The E-PA solution at physiological $\mathrm{pH}$ shows the formation of random coil with least signal at $195 \mathrm{~nm}$. The random coil structure of E-PA disappears and transforms into $\beta$-sheet structure either by lowering the $\mathrm{pH}$ or by introducing the iron ions due to the self-assembly process. The CD results also prove the self-assembly of Phos-PA molecules at $\mathrm{pH} 7$ due to the presence of $\beta$-sheet structural motif.

The transmission electron microscopy (TEM) images of both self-assembled E-PA and Phos-PA after addition of $\mathrm{FeCl}_{3}$ revealed nanostructure formation. On the one hand, the E-PA and $\mathrm{FeCl}_{3}$ complex forms one-dimensional (1-D) nanobelt with a width of $60 \mathrm{~nm}$ (Figure 1d). On the other hand, the mixture of Phos-PA and $\mathrm{FeCl}_{3}$ forms 1-D nanofiber with a diameter of 10 $\mathrm{nm}$ (Figure 1e). The $\beta$-sheet conformation in both selfassembled Phos-PA and E-PA systems contributed to the nanofiber and nanobelt formation. Glutamic acid side chain plays a major role in the self-assembly of the E-PA molecule. In addition, the nanobelt structure is related with highly effective packing among $\beta$-sheets with peptide segments leading to the loss of curvature in the aggregate. ${ }^{32}$ The $\mathrm{CD}$ spectra support the $\beta$-sheet content of the E-PA $/ \mathrm{FeCl}_{3}$ that is higher than the E-PA forming nanofiber at acidic $\mathrm{pH}$ (Figure S6). On the one hand, the ETF shows inorganic material covering the 1-D peptide nanobelts (Figure 1f). On the other hand, the PTF forms nanofibers with inorganic $\mathrm{FePO}_{4}$ on the surface of the peptide nanofiber core (Figure 1g).

Calcination was performed to obtain amorphous forms of anhydrous $\mathrm{FePO}_{4}$ that has better capacity and cyclability than trigonal, hexagonal, and hydrated $\mathrm{FePO}_{4}{ }^{33}$ After calcination of ETF, on the one hand, the $\mathrm{FePO}_{4}$ nanobelts were sintered (Figure $2 \mathrm{a}$ ). On the other hand, the organic-inorganic coreshell nanofibers of PTF were transformed into nanotubes due to the decomposition of organic template. The average wall thickness of PTF nanotube after calcination is $\sim 8 \mathrm{~nm}$ (Figure $2 \mathrm{~d}$ ). High-resolution TEM images of both samples show the presence of amorphous surface (Figure S7).

The morphology of both calcined and uncalcined ETF and PTF samples were also confirmed by using E-SEM (Figures $2 \mathrm{~b}, \mathrm{e}$ and S8). After calcination, the network is thoroughly preserved as shown in the SEM micrographs. The EDX spectra of the calcined $\mathrm{FePO}_{4}$-coated peptide nanostructures show $\mathrm{Fe}, \mathrm{P}$, and $\mathrm{O}$ peaks in EDX spectrum of both samples (Figure 2c,f). For calcined ETF, 
a

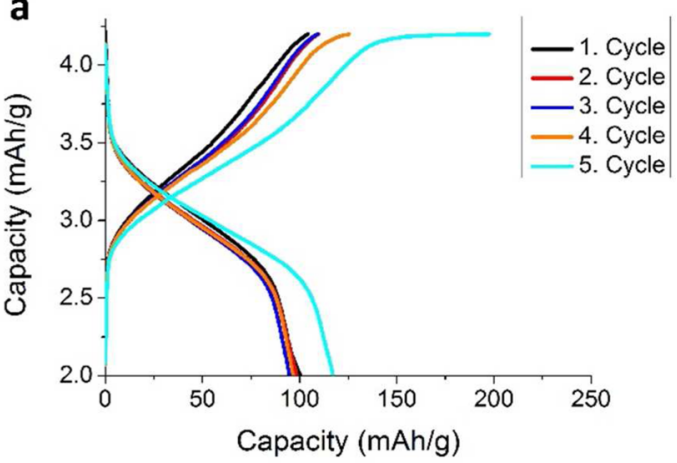

b

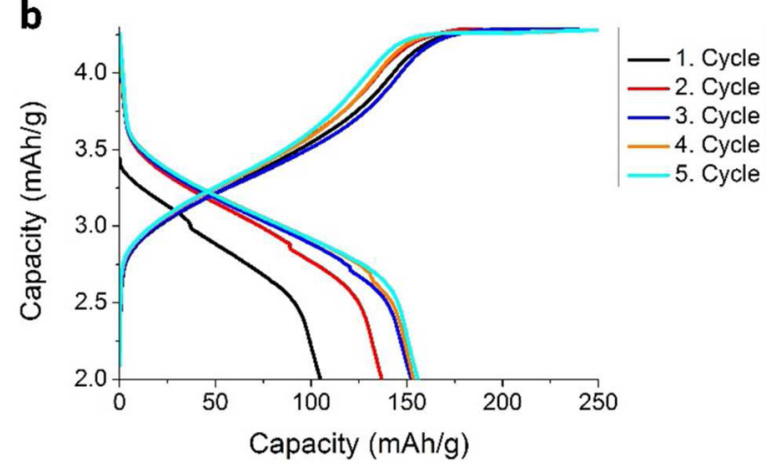

Figure 4. Five cycles of the templated $\mathrm{FePO}_{4}$ at a current rate of $\mathrm{C} / 20$ with higher potential ranges. (a) ETF nanobelt at 2-4.2 V, (b) PTF nanotube 2$4.3 \mathrm{~V}$.

the $\mathrm{Fe} / \mathrm{P}$ atomic ratio is found to be 0.92 , and the $\mathrm{Fe} / \mathrm{P}$ atomic ratio of calcined PTF is 0.99 .

The FT-IR analysis was performed to understand the interactions in the organic-inorganic core-shell materials (Figure S9). The uncalcined ETF, uncalcined PTF, calcined ETF, calcined PTF, and template-free (bulk) $\mathrm{FePO}_{4}$ show peaks, which belong to peptide and iron phosphate. Crystallinity of the organic-inorganic core-shell materials was analyzed by using Xray diffractometer (XRD). A broad peak was observed for each sample: uncalcined ETF, uncalcined PTF, calcined ETF, and calcined PTF indicating the presence of amorphous phase in all samples (Figure S10a). The purity of the crystalline $\mathrm{FePO}_{4}$ was proved by heating both ETF and PTF until $600{ }^{\circ} \mathrm{C}$ for $2 \mathrm{~h}$ to form crystalline $\mathrm{FePO}_{4}$. The patterns of crystalline structure of $\mathrm{FePO}_{4}$ according to the reference from ICSD hexagonal $\mathrm{FePO}_{4}$ code 01-084-0875 were observed from the $\mathrm{FePO}_{4}$ samples (Figure S10c,d). ${ }^{34}$ The X-ray photoelectron spectroscopy (XPS) was used to characterize organic-inorganic core-shell peptide and $\mathrm{FePO}_{4}$ nanostructures. XPS spectra of uncalcined and calcined $\mathrm{FePO}_{4}$ samples show peaks corresponding to $\mathrm{Fe} 2 \mathrm{p}, \mathrm{Fe}$ $3 \mathrm{p}, \mathrm{O} 1 \mathrm{~s}, \mathrm{~N} 1 \mathrm{~s}, \mathrm{C} 1 \mathrm{~s}, \mathrm{P} 2 \mathrm{~s}$, and P 2p (Figures S11-S13).

A thermogravimetric analysis was performed to determine the quantity of organic and inorganic materials in uncalcined ETF and PTF (Figure S14). Both of the template-directed $\mathrm{FePO}_{4}$ materials before calcination consist of nearly $65 \%$ of inorganic materials. Inductively coupled plasma-mass spectrometry (ICPMS) analyses were also conducted to determine the amount of $\mathrm{FePO}_{4}$ in each calcined sample. The iron phosphate content in 1 mg of each of the calcined E-PA/ $/ \mathrm{PeO}_{4}, \mathrm{Phos}-\mathrm{PA} / \mathrm{FePO}_{4}$, and template-free $\mathrm{FePO}_{4}$ are found to be $80.65 \%, 67.46 \%$, and $71.54 \%$, respectively. The $\mathrm{FePO}_{4}$ amount in each calcined powder was used for calculating the weight of the active material in the cathode material to obtain the capacity value.

Electrochemical performances of the template-grown $\mathrm{FePO}_{4}$ cathodes were studied with discharge-charge tests in the voltage range of 2.0-4.0 V (Figure 3). The discharge-charge curves at different current rates for all of the materials were given in detail in Figures S15-S17, in which the first charge capacity of the ETF was also shown up to completion. The ETF, the PTF, and the bulk template-free $\mathrm{FePO}_{4}$ revealed first discharge capacities of 116,106 , and $18 \mathrm{mAh} / \mathrm{g}$ at $\mathrm{C} / 20$ current rate, respectively (Figures 3a,b and S17a). Clearly, the template-grown $\mathrm{FePO}_{4}$ materials yielded significantly greater discharge capacities (around sixfold discharge capacity increase for the ETF and the PTF). All materials showed high charge capacities and a charge plateau at $\sim 3.35 \mathrm{~V}$ in the first few cycles at a current rate of
$\mathrm{C} / 20$, indicating presence of some side reactions, which results in low Coulombic efficiencies. These reactions can potentially occur with water molecules ${ }^{35}$ and side products (Figures S10S13) formed during the synthesis. The reactions are less pronounced in the templated materials than in the bulk material, as the peptide templates restrain the formation of oxides/ hydroxides by electrostatically attracting the $\mathrm{Fe}^{3+}$ cations to form well-arranged $\mathrm{FePO}_{4}$ nucleation sites. ${ }^{33}$ Furthermore, the discharge capacity of the ETF increased to $127 \mathrm{mAh} / \mathrm{g}$, it stayed the same for the PTF after seven cycles at $\mathrm{C} / 20$ current rate, while it was $24 \mathrm{mAh} / \mathrm{g}$ at $\mathrm{C} / 20$ for the bulk $\mathrm{FePO}_{4}$.

The rate capabilities of the materials were studied with current rates of $\mathrm{C} / 10, \mathrm{C} / 5$, and $\mathrm{C}$ (Figure $3 \mathrm{c}$ ). The rate capability of the PTF was observed to be superior to that of the ETF. The PTF sample yielded average discharge capacities of 117,92 , and 28 $\mathrm{mAh} / \mathrm{g}$ in each current rate, respectively. In the ETF, the average discharge capacities were 108, 76, and $21 \mathrm{mAh} / \mathrm{g}$, respectively, while they were 26,18 , and $7 \mathrm{mAh} / \mathrm{g}$ for the bulk $\mathrm{FePO}_{4}$. The poor rate capability behavior as well as the low discharge capacities of the bulk are related to the long Li-ion intercalation distances, low surface-to-volume ratio, which results in lower electrochemical reactivity and also lower areal contact with the electronic conductor MWCNT in the bulk. The bioinspired growth method successfully overcomes most of these problems, as it provides smaller particle size. Moreover, the 1-D peptide nanobelt template of the ETF, which had a $60 \mathrm{~nm}$ width (Figure $1 d)$, was sintered after the calcination process, while 1-D nanofiber template of PTF, whose diameter was $10 \mathrm{~nm}$ (Figure le), decomposed upon calcination and formed nanotubes of templated $\mathrm{FePO}_{4}$, which had a wall thickness of $8 \mathrm{~nm}$ (Figure $2 \mathrm{~d})$. As a result, the particle size in the PTF is smaller than in the ETF, and the phosphate groups present on the Phos-PA molecules provide enhanced order during deposition of $\mathrm{FePO}_{4}$. The ordered structure and the reduced length of $\mathrm{Li}^{+}$ion transportation path provides superior electrochemical performance to the PTF. Furthermore, note that the decrease in the discharge capacities of the templated materials at higher current rates could be related to the reducing effect on the electronic conductivities of the materials due to the remaining organic species after calcination.

To understand the stability of prepared materials at high current rate, the cells were tested with $\mathrm{C} / 20$ current rate for five cycles after the rate capability measurements. The capacity increased to 135,137 , and $27 \mathrm{mAh} / \mathrm{g}$ for the PTF, the ETF, and the bulk $\mathrm{FePO}_{4}$, respectively. The enhancement in the capacity at the same current rate is attributed to the surface activation and 
ion channel formation as a result of repeated cycling. ${ }^{36}$ Although the initial discharge capacity of the PTF nanotube was lower than that of the ETF nanobelt, it demonstrated comparable capacity at the end of the rate capability tests, and the PTF showed better performance at higher current rates.

The stability of the templated materials was further analyzed by cycling the cells at $\mathrm{C} / 2$ current rate for 50 cycles (Figure $3 \mathrm{~d}$ ). In addition, five cycles of the bulk $\mathrm{FePO}_{4}$ at $\mathrm{C} / 5$ current rate were also provided for comparison. The biotemplate grown materials provided stable capacities over 50 cycles, which are much higher compared to the bulk material's capacity. The ETF and the PTF revealed 67 and $91 \mathrm{mAh} / \mathrm{g}$ discharge capacities at the end of the tests, respectively. The average Coulombic efficiencies for the ETF, the PTF, and the bulk were 91.7\%, 95.9\%, and 83\%, respectively (Figure S18). Clearly, the effect of the reduced size increased the reversibility of the electrochemical reaction. Furthermore, the ETF showed an increased trend in the Coulombic efficiency, while the PTF had a rather higher and stable value. This observation supports that the structure of the ETF becomes more ordered upon cycling as mentioned before, while the PTF retains its order from the beginning.

The stability and the performance of the ETF and the PTF samples were further tested at $\mathrm{C} / 20$ current rate with higher potential ranges of $2-4.2 \mathrm{~V}$ and $2-4.3 \mathrm{~V}$, respectively, which are frequently used cutoff potentials in the literature in addition to $2-4 \mathrm{~V}$ potential range (Figure 4$){ }^{28,36}$ The discharge capacity of the templated nanotubular $\mathrm{FePO}_{4}$ (PTF) was increased to 155 $\mathrm{mAh} / \mathrm{g}$, which is higher than its initial capacity with the low potential range $(2-4 \mathrm{~V})$ at $\mathrm{C} / 20$ current rate $(106 \mathrm{mAh} / \mathrm{g})$. These results further prove that the capacity increases gradually with surface activation. The discharge capacity of the templated nanobelt-shaped material (the ETF), however, was $117 \mathrm{mAh} / \mathrm{g}$ after five cycles, which shows that the material has a lower electrochemical stability compared to the PTF.

When the performance of the biomineralized $\mathrm{FePO}_{4}$ nanostructures was compared to previous reports, ${ }^{28}$ the PTF showed better overall discharge capacities than the M13 virustemplated $\mathrm{FePO}_{4}$ (before $\mathrm{AgCl}$ addition). In another example, ${ }^{32}$ the amorphous $\mathrm{LiFePO}_{4}(\sim 102 \mathrm{mAh} / \mathrm{g}$ at C/100 current rate) prepared with a solution-based synthesis had lower capacity than the ETF and the PTF samples. The discharge capacities, rate capabilities, cycling stabilities, and the Coulombic efficiencies of the biotemplated materials are far better than those of the bulk material. Even though the discharge capacity of the PTF was initially slightly lower than that of the ETF, it showed a better performance at higher current rates, and because of its increasing capacity trend, it revealed a higher discharge capacity at the same current rate $(C / 2)$, eventually. Superior performance of the PTF compared to the ETF is attributed to the high surface area of the PTF and chemical characteristics of the peptide nanofibers. Since the Phos-PA peptide contains phosphate groups on the periphery of the nanofibers, the chemical deposition of the $\mathrm{FePO}_{4}$ is more favorable on the phosphate groups, which is more efficient than the E-PA peptide molecule.

\section{CONCLUSION}

In summary, biotemplated amorphous $\mathrm{FePO}_{4}$ nanostructures with an average wall thickness of $8 \mathrm{~nm}$ were synthesized. Significant improvement was observed in the electrochemical performances of the biotemplated materials compared to template-free $\mathrm{FePO}_{4}$ due to nanoscale features with controlled morphology. Biotemplated synthesis method provides an easy, environmentally friendly, cost-efficient, and novel way to produce high-performance battery materials, and this technique can be the key to produce cheaper and more advanced battery materials in the future.

\section{EXPERIMENTAL SECTION}

Materials. 9-Fluorenylmethoxycarbonyl (Fmoc) and tert-butoxycarbonyl (tBoc) protected amino acids, MBHA Rink Amide resin, Fmoc-Glu(OtBu)-Wang resin, and 2-(1H-benzotriazol-1-yl)-1,1,3,3tetramethyluronium hexafluorophosphate (HBTU) were purchased from NovaBiochem and ABCR. Multiwalled carbon nanotubes (MWCT), lithium bis(trifluoromethanesulfonyl) imide (LiTFSI), battery grade ethylene carbonate (EC), and dimethyl carbonate (DMC) were purchased from Sigma-Aldrich. All other chemicals were purchased from Fisher, Merck, Alfa Aesar, Sigma-Aldrich, Dupont, Celgard, or Whatman and used as received, without any further purification.

Peptides Synthesis. Peptide amphiphile molecules were synthesized manually using the method of standard solid peptide synthesis. Two peptide amphiphile molecules, which were E-PA (Lauryl-VVAGE) and Phos-PA (Lauryl-VVAGEK(phosphonoacetyl)-Am), were synthesized on Fmoc-Glu(OtBu)-Wang resin and MBHA Rink Amide resin, respectively. Before attaching the first amino acid residue to the resin, the Fmoc protecting group on the resin was removed by treating the resin with $20 \%(\mathrm{v} / \mathrm{v})$ piperidine/dimethylformamide (DMF) solution for $20 \mathrm{~min}$. Amino acid couplings were performed by pouring amino acid solutions containing 2 equiv of $\mathrm{N}$-protected amino acid activated with 1.95 equiv of HBTU and 3 equiv of diisopropylethylamine (DIEA) for 1 equiv mol of resin and agitated for at least $2 \mathrm{~h}$. For Phos-PA, the protecting group ( $\mathrm{Mtt}$ ) at the end of lysine side chain was removed by using $10 \mathrm{~mL}$ of $3.25 \%$ trifluoroacetic acid (TFA), $0.125 \%$ water, $0.125 \%$ triisopropylsilane, and 96.5\% dichloromethane (DCM). Phosphonoacetic acid that was diluted in DMF together with DIEA and HBTU was poured into the vessel and mixed for $1 \mathrm{~d}$ to bind to the side chain of the lysine. Finally, each peptide was cleaved from the resin using a solution of $95 \% \mathrm{TFA}, 2.5 \%$ water, and $2.5 \%$ triisopropylsilane for $2 \mathrm{~h}$. The removal of excess TFA and DCM from the peptide solution was performed by using rotary evaporation. The peptide solution inside of round-bottom flask was dispersed in cold diethyl ether overnight. The peptide amphiphile was separated from diethyl ether by centrifugation. The centrifugate was dissolved in ultrapure water, frozen at $-80^{\circ} \mathrm{C}$, and then lyophilized. The peptide was purified by using preparatory highperformance liquid chromatography (HPLC) before use. Purity of the peptide was ca. $98 \%$.

Templated Iron Phosphate Preparation. Each of the peptide amphiphiles $(1 \mathrm{mg})$ was dissolved in $90 \mu \mathrm{L}$ of ultrapure water to form peptide solutions. The peptide gels were formed by dropping $10 \mu \mathrm{L}$ of iron chloride solution $\left(\mathrm{FeCl}_{3}\right)$ onto the peptide solutions. Each gel was then immersed in iron chloride solution and transferred to ultrapure water to remove the excess iron solution on the gel before immersing into sodium phosphate $\left(\mathrm{NaH}_{2} \mathrm{PO}_{4}\right)$ solution. The gels were again washed with ultrapure water. These steps were repeated for four cycles. All of the processes were performed at low temperature $\left(4{ }^{\circ} \mathrm{C}\right)$ to suppress the hydrolysis of $\mathrm{Fe}^{3+}$ ions. The gels of $\mathrm{E}-\mathrm{PA} / \mathrm{FePO}_{4}$ (ETF) and Phos-PA/ $/ \mathrm{FeO}_{4}$ (PTF) were dehydrated using ethanol before transferring into critical point dryer to produce aerogels. The thermal treatment (calcinations) was performed to the aerogels step by step in normal air atmosphere. The temperature was increased with a heating rate of $5{ }^{\circ} \mathrm{C} / \mathrm{min}$ until $250{ }^{\circ} \mathrm{C}$ and then brought to $350{ }^{\circ} \mathrm{C}$ with heating rate of $1{ }^{\circ} \mathrm{C} / \mathrm{min}$. The samples were kept at $350{ }^{\circ} \mathrm{C}$ for $1 \mathrm{~h}$. Templatefree $\mathrm{FePO}_{4}$ was also prepared by mixing $\mathrm{FeCl}_{3}$ and $\mathrm{NaH}_{2} \mathrm{PO}_{4}$ and kept inside the oven at $80^{\circ} \mathrm{C}$ overnight. The wet powder was calcined by the same procedure as the templated iron phosphate.

Lithium-Ion Battery Preparation. Templated $\mathrm{FePO}_{4}$ cathode films were produced with two different organic templates and tested against lithium metal electrode in Swagelok type cells. The cathode film was obtained by slurry casting, in which the $\mathrm{FePO}_{4}$ powder was ground together with MWCT. Afterward, Nafion binder was dropped to the mixture powder. The composition of the mixture according to the total mass of the mixture was 7:2:1 for $\mathrm{FePO}_{4}, \mathrm{MWCT}$, and Nafion, 
respectively. The mixture was dispersed in isopropanol and stirred for a couple of days using magnetic stirrer. The mixture solution was casted on a separator (Celgard) film with doctor blade technique to yield the desired thickness. The casted film was first dried in room temperature for $1 \mathrm{~h}$, and then the drying process was continued at $60^{\circ} \mathrm{C}$ for $8 \mathrm{~h}$. The average cathode film weight for the all the materials was $\sim 1.0 \mathrm{mg}$. Stainless steel current collectors and two different separators were used (Celgard separator at the $\mathrm{Li}$ anode and Glassfiber/C separator at the cathode side). $280 \mu \mathrm{L}$ of $0.5 \mathrm{M}$ LiTFSI in EC-DMC (1:1) was used as electrolyte. After the cell was assembled in the Ar atmosphere, it was sealed to prevent the interaction with the atmosphere. The cells were rested at room temperature for $8 \mathrm{~h}$ prior to testing.

Liquid Chromatography-Mass Spectrometry. Analytical LCMS measurements were performed using Agilent Technologies 6530 Accurate-Mass Q-TOF LC-MS with electrospray ionization (ESI) source. Agilent Zorbax Extend-C18 column was used together with mixture of two different solutions of $0.1 \%(\mathrm{v} / \mathrm{v})$ ammonium hydroxidewater (A) and $0.1 \%(\mathrm{v} / \mathrm{v})$ ammonium hydroxide-acetonitrile (B). Liquid chromatograms were obtained at $220 \mathrm{~nm}$.

Circular Dichroism. The secondary structure of the peptide nanostructures was determined by using JASCO J815 CD spectrometer at room temperature. One millimeter path quartz cuvette was used to perform the measurements. Aliquots $(300 \mu \mathrm{L})$ of diluted peptide solutions were added into quartz cell and measured from 300 to $190 \mathrm{~nm}$, with data interval and data pitch of $0.1 \mathrm{~nm}$, scanning speed of $100 \mathrm{~nm} /$ min, and three times of accumulations. Digital integration time was selected as $1 \mathrm{~s}$, bandwidth as $1 \mathrm{~nm}$, and sensitivity as standard.

Environmental-Scanning Electron Microscopy. The morphology of the fabricated samples was visualized by using FEI Quanta 200 FEG environmental scanning electron microscope with an ETD detector. The samples were sputter coated with $8 \mathrm{~nm}$ of gold/palladium prior to imaging. The EDX spectra of the samples were collected from the area at $300 \times$ magnification of the noncoated samples to obtain the chemical composition. The quantification of the EDX spectra was made to obtain the $\mathrm{Fe} / \mathrm{P}$ ratio in the samples.

Transmission Electron Microscopy and Scanning Electron Microscopy. The diluted samples were casted on a Lacey mesh ultrathin carbon-coated copper grid and observed by FEI Tecnai G2 F30. Negative staining was performed using $2 \%(\mathrm{w} / \mathrm{v})$ uranyl acetate for samples that did not contain any inorganic residue to get better contrast images.

Thermal Gravimetric Analysis. The percent composition of inorganic content in templated $\mathrm{FePO}_{4}$ samples was determined by using a thermogravimetric analyzer (TGA; Q500, TA Instruments). The temperature was ramped from 25 to $500{ }^{\circ} \mathrm{C}$ with $10{ }^{\circ} \mathrm{C} \mathrm{min}{ }^{-1}$ heating rate in the presence of $\mathrm{N}_{2}$ gas. $\mathrm{N}_{2}$ gas was switched to $\mathrm{O}_{2}$ gas after the temperature reached $500{ }^{\circ} \mathrm{C}$. The heating process was continued until $800^{\circ} \mathrm{C}$ with the same heating rate.

Fourier Transform Infrared Spectroscopy. Qualitative analysis of the samples was performed by analyzing the infrared absorption spectrum of each sample to learn the interaction inside the samples. $\mathrm{KBr}$ pellet was prepared prior to measurement. Bruker Vertex 70 FT-IR spectrometer was used for FT-IR analysis with wavenumber range from 4000 to $400 \mathrm{~cm}^{-1}$.

X-ray Diffractometer. The crystal structure of the samples was studied by using PAN analytical X'Pert X-ray diffractometer with $\mathrm{Cu} \mathrm{K} \alpha$ radiation. The sample powders were scanned in the range of $2 \theta=10-$ $60^{\circ}$ and step size of $0.026^{\circ}$.

X-ray Photoelectron Spectroscopy. The surface characterization of organic-inorganic core-shell samples was done by using a Thermo Scientific K-Alpha XPS spectrometer with Al K $\alpha$ monochromatic (100$400 \mathrm{eV}$ range) X-ray source and ultrahigh vacuum ( $\sim 10-9$ torr).

Inductively Coupled Plasma-Mass Spectrometry. The iron content in the samples was determined by using Thermo Scientific X Series 2 ICP-MS. The iron amount was used to calculate the percentage of iron phosphate in the sample. Five different concentrations of iron reference solutions $(50,100,250,500$, and $1000 \mathrm{ppb})$ were prepared from $1000 \mathrm{ppm}$ iron standard solution.

Multichannel Battery Testing System. Electrochemical testing of the cells was performed with a Landt CT2001A multichannel potentiostat/galvanostat. Five discharge/charge cycles are applied to the cell with current rates of $\mathrm{C} / 20, \mathrm{C} / 10, \mathrm{C} / 5$, and $\mathrm{C}$, while the voltage was first limited to $2.0-4.0 \mathrm{~V}$; then, new voltage ranges of $2.0-4.2$ and $2.0-4.3 \mathrm{~V}$ were utilized.

\section{ASSOCIATED CONTENT}

\section{Supporting Information}

The Supporting Information is available free of charge on the ACS Publications website at DOI: 10.1021/acsami.6b02528.

Detailed description of the LC-MS chromatograms; gel formation of peptides under different conditions; transmission and scanning electron micrographs of selfassembled peptide amphiphiles; FT-IR, XRD, and XPS data of templated and template-free $\mathrm{FePO}_{4}$; TGA of assynthesized $\mathrm{FePO}_{4}$; charge and discharge curve of $\mathrm{FePO}_{4}$ samples; Coulombic efficiencies of templated $\mathrm{FePO}_{4}$. (PDF)

\section{AUTHOR INFORMATION}

\section{Corresponding Authors}

*E-mail: moguler@unam.bilkent.edu.tr. (M.O.G.)

*E-mail: yilmaz@unam.bilkent.edu.tr. (E.Y.)

\section{Present Address}

${ }^{\S}$ Division of Biological and Environmental Sciences and Engineering, King Abdullah University of Science and Technology, Thuwal 23955-6900, Kingdom of Saudi Arabia.

\section{Notes}

The authors declare no competing financial interest.

\section{ACKNOWLEDGMENTS}

This work was partially funded by TUBITAK Grant No. 113M900. We thank Dr. A. Shaikh for help in peptide synthesis and M. Guler for TEM imaging.

\section{REFERENCES}

(1) Tarascon, J. M.; Armand, M. Issues and Challenges Facing Rechargeable Lithium Batteries. Nature 2001, 414 (6861), 359-367.

(2) Armand, M.; Tarascon, J. M. Building Better Batteries. Nature 2008, 451 (7179), 652-657.

(3) Chen, J. S.; Archer, L. A.; Wen Lou, X. SnO ${ }_{2}$ Hollow Structures and $\mathrm{TiO}_{2}$ Nanosheets for Lithium-Ion Batteries. J. Mater. Chem. 2011, 21 (27), 9912-9924.

(4) Yin, Y.; Hu, Y.; Wu, P.; Zhang, H.; Cai, C. A Graphene-Amorphous $\mathrm{FePO}_{4}$ Hollow Nanosphere Hybrid as a Cathode Material for Lithium Ion Batteries. Chem. Commun. 2012, 48 (15), 2137-2139.

(5) Cho, J.; Kim, Y.J.; Kim, T.-J.; Park, B. Enhanced Structural Stability of o-LiMnO 2 by Sol-Gel Coating of $\mathrm{Al}_{2} \mathrm{O}_{3}$. Chem. Mater. 2001, 13 (1), $18-20$.

(6) Recham, N.; Chotard, J. N.; Dupont, L.; Delacourt, C.; Walker, W.; Armand, M.; Tarascon, J. M. A 3.6 V Lithium-Based Fluorosulphate Insertion Positive Electrode for Lithium-Ion Batteries. Nat. Mater. 2010, $9(1), 68-74$

(7) Kang, K.; Meng, Y. S.; Bréger, J.; Grey, C. P.; Ceder, G. Electrodes with High Power and High Capacity for Rechargeable Lithium Batteries. Science 2006, 311 (5763), 977-980.

(8) Ji, X.; Lee, K. T.; Nazar, L. F. A Highly Ordered Nanostructured Carbon-Sulphur Cathode for Lithium-Sulphur Batteries. Nat. Mater. 2009, 8 (6), 500-506.

(9) Padhi, A. K.; Nanjundaswamy, K. S.; Goodenough, J. B. PhosphoOlivines as Positive-Electrode Materials for Rechargeable Lithium Batteries. J. Electrochem. Soc. 1997, 144 (4), 1188-1194.

(10) Wu, X.-L.; Jiang, L.-Y.; Cao, F.-F.; Guo, Y.-G.; Wan, L.-J. LiFePO Nanoparticles Embedded in a Nanoporous Carbon Matrix: Superior Cathode Material for Electrochemical Energy-Storage Devices. Adv. Mater. 2009, 21 (25-26), 2710-2714. 
(11) Chung, S.-Y.; Bloking, J. T.; Chiang, Y.-M. Electronically Conductive Phospho-Olivines as Lithium Storage Electrodes. Nat. Mater. 2002, 1 (2), 123-128.

(12) Wang, C.; Hong, J. Ionic/Electronic Conducting Characteristics of $\mathrm{LiFePO}_{4}$ Cathode Materials: The Determining Factors for High Rate Performance. Electrochem. Solid-State Lett. 2007, 10 (3), A65-A69.

(13) Yang, S.; Song, Y.; Zavalij, P. Y.; Stanley Whittingham, M. Reactivity, Stability and Electrochemical Behavior of Lithium Iron Phosphates. Electrochem. Commun. 2002, 4 (3), 239-244.

(14) Zhang, S. M.; Zhang, J. X.; Xu, S. J.; Yuan, X. J.; He, B. C. Li Ion Diffusivity and Electrochemical Properties of $\mathrm{FePO}_{4}$ Nanoparticles Acted Directly as Cathode Materials in Lithium Ion Rechargeable Batteries. Electrochim. Acta 2013, 88, 287-293.

(15) Liu, Y.; Xu, S.; Zhang, S.; Zhang, J.; Fan, J.; Zhou, Y. Direct Growth of $\mathrm{FePO}_{4} /$ Reduced Graphene Oxide Nanosheet Composites for the Sodium-Ion Battery. J. Mater. Chem. A 2015, 3 (10), 5501-5508.

(16) Shi, Z. C.; Attia, A.; Ye, W. L.; Wang, Q.; Li, Y. X.; Yang, Y. Synthesis, Characterization and Electrochemical Performance of Mesoporous $\mathrm{FePO}_{4}$ as Cathode Material for Rechargeable Lithium Batteries. Electrochim. Acta 2008, 53 (6), 2665-2673.

(17) Arico, A. S.; Bruce, P.; Scrosati, B.; Tarascon, J.-M.; van Schalkwijk, W. Nanostructured Materials for Advanced Energy Conversion and Storage Devices. Nat. Mater. 2005, 4 (5), 366-377.

(18) Taberna, P. L.; Mitra, S.; Poizot, P.; Simon, P.; Tarascon, J. M. High Rate Capabilities $\mathrm{Fe}_{3} \mathrm{O}_{4}$-Based Cu Nano-Architectured Electrodes for Lithium-Ion Battery Applications. Nat. Mater. 2006, 5 (7), 567-573.

(19) Lee, Y. J.; Yi, H.; Kim, W.-J.; Kang, K.; Yun, D. S.; Strano, M. S.; Ceder, G.; Belcher, A. M. Fabricating Genetically Engineered HighPower Lithium-Ion Batteries Using Multiple Virus Genes. Science 2009, 324 (5930), 1051-1055.

(20) Tarascon, J. M.; Delacourt, C.; Prakash, A. S.; Morcrette, M.; Hegde, M. S.; Wurm, C.; Masquelier, C. Various Strategies to Tune the Ionic/Electronic Properties of Electrode Materials. Dalton Trans. 2004, No. 19, 2988-2994.

(21) Croce, F.; D’ Epifanio, A.; Hassoun, J.; Deptula, A.; Olczac, T.; Scrosati, B. A Novel Concept for the Synthesis of an Improved $\mathrm{LiFePO}_{4}$ Lithium Battery Cathode. Electrochem. Solid-State Lett. 2002, 5 (3), A47-A50.

(22) Hu, Y. S.; Guo, Y. G.; Dominko, R.; Gaberscek, M.; Jamnik, J.; Maier, J. Improved Electrode Performance of Porous $\mathrm{LiFePO}_{4}$ Using $\mathrm{RuO}_{2}$ as an Oxidic Nanoscale Interconnect. Adv. Mater. 2007, 19 (15), $1963-1966$.

(23) Lin, H.-P.; Mou, C.-Y. Structural and Morphological Control of Cationic Surfactant-Templated Mesoporous Silica. Acc. Chem. Res. 2002, 35 (11), 927-935.

(24) Schüth, F. Endo- and Exotemplating to Create High-Surface-Area Inorganic Materials. Angew. Chem., Int. Ed. 2003, 42 (31), 3604-3622.

(25) Valdés-Solís, T.; Fuertes, A. B. High-Surface Area Inorganic Compounds Prepared by Nanocasting Techniques. Mater. Res. Bull. 2006, 41 (12), 2187-2197.

(26) Cheng, F.; Tao, Z.; Liang, J.; Chen, J. Template-Directed Materials for Rechargeable Lithium-Ion Batteries. Chem. Mater. 2008, 20 (3), 667-681.

(27) Cao, F.; Li, D. Biotemplate Synthesis of Monodispersed Iron Phosphate Hollow Microspheres. Bioinspiration Biomimetics 2010, 5 (1), 016005.

(28) Lee, Y. J.; Belcher, A. M. Nanostructure Design of Amorphous $\mathrm{FePO}_{4}$ Facilitated by a Virus for $3 \mathrm{~V}$ Lithium Ion Battery Cathodes. J. Mater. Chem. 2011, 21 (4), 1033-1039.

(29) Ceylan, H.; Ozgit-Akgun, C.; Erkal, T. S.; Donmez, I.; Garifullin, R.; Tekinay, A. B.; Usta, H.; Biyikli, N.; Guler, M. O. Size-Controlled Conformal Nanofabrication of Biotemplated Three-Dimensional $\mathrm{TiO}_{2}$ and ZnO Nanonetworks. Sci. Rep. 2013, 3.10.1038/srep02306

(30) Xu, X.-D.; Chen, C.-S.; Lu, B.; Cheng, S.-X.; Zhang, X.-Z.; Zhuo, R.-X. Coassembly of Oppositely Charged Short Peptides into WellDefined Supramolecular Hydrogels. J. Phys. Chem. B 2010, 114 (7), 2365-2372.

(31) Kubelka, J.; Keiderling, T. A. Differentiation of $\beta$-Sheet-Forming Structures: Ab Initio-Based Simulations of IR Absorption and
Vibrational CD for Model Peptide and Protein $\beta$-Sheets. J. Am. Chem. Soc. 2001, 123 (48), 12048-12058.

(32) Zhu, C.; Mu, X.; Popovic, J.; Weichert, K.; van Aken, P. A.; Yu, Y.; Maier, J. Lithium Potential Variations for Metastable Materials: Case Study of Nanocrystalline and Amorphous $\mathrm{LiFePO}_{4}$. Nano Lett. 2014, 14 (9), 5342-5349.

(33) Guo, C. X.; Shen, Y. Q.; Dong, Z. L.; Chen, X. D.; Lou, X. W.; Li, C. M. DNA-Directed Growth of $\mathrm{FePO}_{4}$ Nanostructures on Carbon Nanotubes to Achieve Nearly $100 \%$ Theoretical Capacity for LithiumIon Batteries. Energy Environ. Sci. 2012, 5 (5), 6919-6922.

(34) Moradi, M.; Li, Z.; Qi, J.; Xing, W.; Xiang, K.; Chiang, Y.-M.; Belcher, A. M. Improving the Capacity of Sodium Ion Battery Using a Virus-Templated Nanostructured Composite Cathode. Nano Lett. 2015, 15 (5), 2917-2921.

(35) Son, D.; Kim, E.; Kim, T.-G.; Kim, M. G.; Cho, J.; Park, B. Nanoparticle Iron-Phosphate Anode Material for Li-Ion Battery. Appl. Phys. Lett. 2004, 85 (24), 5875-5877.

(36) Dou, H.; Nie, P.; MacFarlane, D. R. Mechano-Chemical Synthesis of Nanostructured $\mathrm{FePO}_{4} / \mathrm{MWCNT}$ Composites as Cathode Materials for Lithium-Ion Batteries. J. Mater. Chem. A 2014, 2 (45), 19536-19541. 